\section{而 Heighten Science \\ P U B L I C I T I O N S Corporation ISSN \\ 2640-2793}

\title{
Brain response in some systemic immune condition-Toxicological aspects
}

\author{
Luisetto $\mathrm{M}^{*}$ \\ Applied Pharmacologist, European Specialist Lab Medicine, Independent Researcher, 29121, \\ Italy
}

*Address for Correspondence: Luisetto M,

Applied Pharmacologist, European Specialist Lab Medicine, Independent Researcher, 29121 Italy, Email: maurolu65@gmail.com

Submitted: 30 November 2017

Approved: 22 December 2017

Published: 26 December 2017

Copyright: @ 2017 Luisetto M. This is an open access article distributed under the Creative Commons Attribution License, which permits unrestricted use, distribution, and reproduction in any medium, provided the original work is properly cited.

Keywords: Toxicology; Brain pathology; Immune status; New pharmacological strategies

Check for updates

\section{Abstract}

From biomedical literature "autism disorder are involved in young patient, that we have abnormalities (Imaging, histology) in some brain areas, and a comples symptomatology. Genetic and environment can produce some unbalances in brain grow and immunitary situation is involved. Apoptotic signal contribute in brain growth and immunologic shock can unbalance the environment producing abnormalities."

We can see that some pharmacological molecules are been introduced in therapy in some brain pathologies with a specific mechanism: modulating the immune systems. We can see that some systemic immune modifications can unbalance this systems producing pharmacological effect in local place (as Brain). We can observe this phenomena like a kind of toxicity that can be deeply investigate to discover new Pharmacological strategies.

Aim of this work is to observe this kind of pathologies under a specific immune-toxicological aspect. We think that in this field are needed deeply new approach in order to adequately focus this kind of disorder. A different way to set this kind of pathologies can help in searching new pharmacological strategies.

\section{Introduction}

Under the need of new research hypothesis to verify the pathogenesis of some brain disorder we try to observe under a specific immune- toxicological aspect in order to search new pharmacological strategies.

We start this work observing the SM pathology that is consider an organ specific disease. In this kind of pathology we have a specific role of Flogosis event $s$ and leucocyte migration, amplification of immune reactions with enrollment of monocytes, macrophages, T CELLS cytotoxic and plasma cells from periferical blood.

\section{Currently in Therapy SM some strategies in use as immune modifier}

- Metilprednisolon.

- Fingolimod, receptor modulator sfingosin-1-fosfate (S1P), localizaed on linfocite surfaces and able to across the haemato-encefalic barrier.

- Antagonists S1P receptors in linfocite, inibite linfocite properties of come out from limphonodes (redistribuitions) with reducing infiltration of linphocites in SNC (involved in nerve flogosis and tissue damage).

In 4-6 hours after sub ministration we can observe reduction of linphocites in periferical blood (75\%). And in 2 weeks $30 \%$ in reducing lymphocyte counts. After stopped subministration increase periferical limphocite. (Normal level in 1-2 months). 
- Interferon beta reduce SNC flogosis, reduce linphocite T activation, and pass through the SNC tissue.

- Mitoxantron immunosuppressor uso per SM in fasi RR, SP, Ciclofosfamide etc.

- Natalizumab directed to $\alpha 4$ della $\alpha 4 \beta 1$ integrin chain , and block binding of "Very Late Antigen" della $\alpha 4 \beta 1$ integrina (VLA4) expressed in all leucocites, with vascular cell molecule of adhesion (VCAM),inibites the binding of leucociti $\alpha$ 4-positive with la Fibronectina (antiapoptotic for i linfocitie T).

Modulate linf. $\mathrm{T}$ transfer from periferical blood to tissue, linfocite $\mathrm{T}$ apoptosis, leucocitary activation. In animal model using MRI was observed reducing in tissue migration of leucocite and reduced plaques after multiple subministration.

- But other molecules are in use in this pathology (old and new) related the specific phases of disease and different kind of disease.

\section{Material and Methods}

This review work has been implemented with an observational and review approach we have analyzed some relevant bibliography in order to verify the general immune status influences with some local situations and the relationship.

\section{Results}

From bio- medical literature we can see:

According Bilbo SD et al., "The brain, endocrine, and immune systems are inextricably linked. Immune molecules have a powerful impact on neuroendocrine function, including hormone-behavior interactions, during health as well as sickness. Similarly, alterations in hormones, such as during stress, can powerfully impact immune function or reactivity. These functional shifts are evolved, adaptive responses that organize changes in behavior and mobilize immune resources, but can also lead to pathology or exacerbate disease if prolonged or exaggerated. The developing brain in particular is exquisitely sensitive to both endogenous and exogenous signals, and increasing evidence suggests the immune system has a critical role in brain development and associated behavioral outcomes for the life of the individual. Indeed, there are associations between many neuropsychiatric disorders and immune dysfunction, with a distinct etiology in neurodevelopment. The goal of this review is to describe the important role of the immune system during brain development, and to discuss some of the many ways in which immune activation during early brain development can affect the later-life outcomes of neural function, immune function, mood and cognition." [1]

Kappos L et al., writed that : "Oral fingolimod, a sphingosine-1-phosphate-receptor modulator that prevents the egress of lymphocytes from lymph nodes, significantly improved relapse rates and end points measured on magnetic resonance imaging (MRI), as compared with either placebo or intramuscular interferon beta-1a, in phase 2 and 3 studies of multiple sclerosis.

In our 24-month, double-blind, randomized study, we enrolled patients who had relapsing-remitting multiple sclerosis, were 18 to 55 years of age, had a score of 0 to 5.5 on the Expanded Disability Status Scale (which ranges from 0 to 10, with higher scores indicating greater disability), and had had one or more relapses in the previous year or two or more in the previous 2 years. Patients received oral fingolimod at a dose of $0.5 \mathrm{mg}$ or $1.25 \mathrm{mg}$ daily or placebo. End points included the annualized relapse rate (the primary end point) and the time to disability progression (a secondary end point).

A total of 1033 of the 1272 patients (81.2\%) completed the study. The annualized relapse rate was 0.18 with $0.5 \mathrm{mg}$ of fingolimod, 0.16 with $1.25 \mathrm{mg}$ of fingolimod, 
and 0.40 with placebo $(\mathrm{P}<0.001$ for either dose vs. placebo). Fingolimod at doses of $0.5 \mathrm{mg}$ and $1.25 \mathrm{mg}$ significantly reduced the risk of disability progression over the 24 -month period (hazard ratio, 0.70 and 0.68 , respectively; $\mathrm{P}=0.02$ vs. placebo, for both comparisons). The cumulative probability of disability progression (confirmed after 3 months) was $17.7 \%$ with $0.5 \mathrm{mg}$ of fingolimod, $16.6 \%$ with $1.25 \mathrm{mg}$ of fingolimod, and $24.1 \%$ with placebo. Both fingolimod doses were superior to placebo with regard to MRI-related measures (number of new or enlarged lesions on T (2)-weighted images, gadolinium-enhancing lesions, and brain-volume loss; $\mathrm{P}<0.001$ for all comparisons at 24 months). Causes of study discontinuation and adverse events related to fingolimod included bradycardia and atrioventricular conduction block at the time of fingolimod initiation, macular edema, elevated liver-enzyme levels, and mild hypertension. As compared with placebo, both doses of oral fingolimod improved the relapse rate, the risk of disability progression, and end points on MRI. These benefits will need to be weighed against possible long-term risks. (Clinical Trials.gov number, NCT00289978.)" [2]

And according luisetto et al. in 2017, "Starting from the evidence that autisms are not elder typical pathology and observing from toxicology and embryology disciplinewe know that the time is relevant in order to predict some kind of Congenic pathologies. We have seen that in embryology are relevant genetic informations, the time, microenvironment factors and their specific time relationship.

From toxicology science we know that some toxic subtancies produce specific toxicity related the contact time in embiologic-fetal life whit minor or major physioanactomic damage. Many factors are involved as cellular mediators and intercellular signals but also environmental factors that can modify heavily the normal neuronal growth and development or connectivity. We have seen from literature a relationship between immunologic status and some brain condition and that in autism we have a reduced neuron- connections and population in some area." [3] "We observed some relevant literature involving the immune system in brain development in order to verify relationship in pathogenesis of autism disorder. We think are relevant in this.

Pervasive developmental disorder: The time of expression, micro-environment, immunologic status and genetic profile. Al this factors can give right response to the next research activities." [3].

\section{Discussion and Conclusion}

We have seen from literature the relationship existing between systemic immune status and local situation like in brain tissue. We can consider under a toxicological view this kind of influences in order to re- consider some brain pathologies expecially if timeage related. (Peaks-age classes more involved in some neurologic pathologies). Local flogosys and related immune reaction activation contribute in some brain pathology and this can be consider a sort of toxicological effect that must to be deeply investigated in order to discover the pathogenetic movens and innovative pharmacological strategies. Toxicology science can add to immunology and pathology to have a more complete vision in some brain patology in time evolution and strategic opportunities. We have seen in example that using fingolimod we have a reduction in linfocites activation and when discontinued this effect reduced (like a discontinue of a toxic substantia). Dose related and time related. FINGOLIMOD Significantly improved relapse rates and end points measured on magnetic resonance imaging (MRI) in objective way. Concepts as toxical doses, time of exposition, cumulative dosage, kinetics, dynamics, methabolism Iatrogenic ADME and other toxicological parameter can be usefully introduced also in neuro-immune toxicology to adeguately focus a physio-pathogenetic phenomena. The results related to the references citated show a specific effect of a systemic drugs in a local place as brain. We think that observing a specific side effect of a drug can be a right method to clear some interference between immunologic status and some development disorder. 


\section{Clarifications}

This work has no any diagnostic or therapeutic intent, only to produce research hypotesys.

\section{References}

1. Bilbo SD, Schwarz JM. The immune system and developmental programming of brain and behavior. Neuroendocrinol. 2012; 33:267-286. Ref.: https://goo.gl/W5CicB

2. Kappos L, Radue EW, O'Connor P, Polman C, Hohlfeld R, et al. A placebo-controlled trial of oral fingolimod in relapsing multiple sclerosis. N Engl J Med. 2010; 362: 387-401. Ref.: https://goo.gl/cm6qnY

3. Luisetto M, Ahmed Yesvi Rafa, Behzad Nili-Ahmadabadi, Farhan Ahmad Khan and Ghulam Rasool Mashori. Immune Shock - Chronologic Event in Some Brain Pathology. Current Opinions in Neurological Science. 1. 2017; 207-215. 